\title{
Elma Çeșitlerine Yapraktan Bor Uygulamasının Bitkinin Mineral Beslenmesiyle Meyvenin Verim ve Kalitesine Etkisi
}

\author{
İbrahim ERDAL* S S Sevkiye Armağan TÜRKAN
}

Süleyman Demirel Üniversitesi, Ziraat Fakültesi, Toprak Bilimi ve Bitki Besleme Bölümü, Isparta

\author{
*Sorumlu yazar e-posta (Corresponding author e-mail) : ibrahimerdal@sdu.edu.tr \\ Geliș tarihi (Received) : 29.06.2016 \\ Kabul tarihi (Accepted): 19.09 .2016
}

\section{Öz}

Bu çalıșmada yapraktan bor gübrelemesinin elma eșitlerinin bor beslenmesiyle verim ve bazı kalite ölçütlerine etkisini incelemek amaçlanmıștır. Denemede Mondial Gala, Red Chief, Scarlet Spur, Breaburn ve Fuji olmak üzere beș elma çeșidi kullanılmıș olup, 0 ve $100 \mathrm{mg} \mathrm{Bl}^{-1}$ litre olacak șekilde hazırlanan çözeltiden, çiçeklenme öncesi 15 gün arayla iki defa yapraktan gübreleme yapıımıștır. Deneme sonunda Braeburn çeșidi hariç diğer çeșitlerin tamamında yaprak B konsantrasyonun arttığı görülmüștür. Yapraktan B gübrelemesiyle bütün çeșitlerin meyve toplam verimi artmıș ve elde edilen artıșlar Mondial Gala ve Breaburn çeșitleri hariç diğerlerinde istatistiksel anlamda önemli olmuștur. Yapraktan bor uygulaması incelenen meyve kalite ölçütlerine genellikle etki yapmamıștır. Çeșitlerin bor uygulamalarından farklı derecelerde etkilendiği görülmüștür.

Anahtar Kelimeler: Bor, çeșit, elma, yapraktan gübreleme

\section{Effect of Foliar Boron Application on Nutrient Concentration, Fruit Yield and Quality of Different Apple Varieties}

\begin{abstract}
In this study, it was aimed to investigate the effect of foliar boron fertilization on different apple varieties. Fort his purposes, five apple varieties as Mondial Gala, Red Chief, Scarlet Spur, Breaburn and Fuji were used. For foliar spraying, 0 and $100 \mathrm{mg} \mathrm{B}^{-1}$ containing solutions were sprayed to the leaves before flowering with fifteen days interval. At the end of the experiment it was seen that leaf boron concentrations increased with foliar boron fertilization in varieties, except for Breaburn. In all varieties, fruit yield increased with the application and the increases obtained were significant in the varieties except for Mondial Gala and Breaburn. In general, leaf boron spraying did not affect significantly examined quality parameters. It was seen that apple varieties were affected differently from the foliar boron fertilization.
\end{abstract}

Key Words: Boron, variety, apple, foliar fertilization

\section{Giriș}

Dünya nüfusunun hızla artması ve tarım birim alandan daha fazla ürün elde etme alanlarındaki artıșın yok denecek kadar az olması, gerekliliğini ortaya çıkarmaktadır. Bunun için yüksek 
verimli yeni çeșitlerin geliștirilmesi yanında, her ürün için uygun bitki yetiștirme tekniklerinin geliștirilmesi gerekmektedir. Bu nedenle son yillarda üretimde ürün kalitesinin geliștirilmesi ve verimin arttırımasında bitki besin elementlerinin yapraktan uygulanması önemli yöntemlerden biri olmuștur. Yüksek toprak pH sı, yüksek kireç içeriği, düșük organik madde, su yetersizliği, yıkanma, diğer besin elementleri arasındaki dengesizlikler, sığ toprak profili, toprak sıkıșması, fiksasyon, topraktan uygulamada geç kalınması, vb. gibi farklı toprak șartlarından dolayı bitki besin elementlerinin kökler vasıtası ile alınamadığı durumlarda, yapraktan uygulama, bitkilerin besin elementi intiyaçlarının karșılanmasında sıkıkla ve bașarıyla kullanmaktadır (Roemheld ve El-Fouly, 1999). Borun bitkide sayısız ișlevi bulunmaktadır (Bergmann, 1992; Kacar ve Katkat 2009, Marschner 2011 ). Boyacı ve Çağlar (2009) tarafindan yapılan bir araștırmada, farklı dozlarda yapraklara uygulanan bor'un badem çeșitlerinde çiçek tozu çimlenme oranını ve meyve tutumunu artırdığı belirlenmiștir. Yürütülen bir çalıșmada yapraktan B uygulaması yapılan elma ağaçlarının yaprak B konsantrasyonunun daha fazla olduğu, net fotosentez oranının, klorofil, stoma iletkenliği, katalaz ve glutation reduktaz enzim aktivitelerinin kontrol gurubu ağaçlarına göre daha fazla olduğu belirlenmiștir. Yine bu çalıșmada yapraktan B uygulamasının meyve verimi ve suda çözünür kuru madde, meyve rengi ve titre edilebilir asitlik gibi bazı kalite ölçütlerini toprak ve kontrol uygulamalarına oranla artırdığı ifade edilmektedir (Wojcik vd., 2008). Yapılan çeșitli çalıșmalarda da yapraktan B uygulamasının, elma çeșitlerinde yaprak B konsantrasyonunu meyve tutumunu ve verimini artırdığı ve bazı verim özelliklerini iyileștirdiği ifade edilmektedir (Wójcik vd., 1999; Neilsen, 2008; Lötze ve Hoffman, 2014). Yapraktan yapılan B uygulamasıyla sadece verim ve kalite kriterleri değil, aynı zamanda elmanın depolanma süresinin uzadığı ve bu süre zarfında kalitesini koruduğu da ifade edilmektedir (Brackmann vd., 2016).

Bu çalıșmada, yapraktan B gübrelemesinin elma çeșitlerinin B beslenmesiyle meyve verimi ve bazı kalite ölçütlerine etkisini incelemek ve çeșitlerin B uygulamasına tepkilerini karșılaștırmak amaçlanmıștır.

\section{MATERYAL VE YÖNTEM}

Araștırma, 2014 yılında Burdur'un Ağlasun ilçesinde üretici bahçesinde yürütülmüș olup, aynı bahçede yetiștirilen 6 yașı Mondial Gala, Red Chief, Scarlet Spur, Braeburn ve Fuji elma çeșitleri denemede kullanılmıștır. Deneme toprağına ait bazı özellikler Çizelge 1' de verilmiștir. Belirtilen çizelgeden de görüleceği üzere, deneme alanı killi tın bünyeli, organik madde içeriği orta, fazla kireçli ve hafif alkali karakterlidir. Toprağın elverișli besin elementlerinden $\mathrm{P}, \mathrm{K}, \mathrm{Mg}$ ve Ca konsantrasyonları yeter ve fazla, $\mathrm{Zn}$ ve Cu konsantrasyonları yeterli, Fe konsantrasyonu orta, Mn konsantrasyonu az, B konsantrasyonu ise çok azdır (Lindsay ve Norvell, 1969; Wolf, 1971; FAO 1990; TOVEP 1991; Eyüpoğlu, 2000).

Denemede B kaynağı olarak ETiBOR ișletmelerinden sağlanan Etidot-67 (\% 20,8 B) gübresi kullanıımıștır. Bu gübreden hazırlanan Y0:0(kontrol) ve $\mathrm{Y}^{1}: 100 \mathrm{mgB}^{-1}$ konsantrasyonlarındaki çözeltilerden, çiçeklenme öncesi 15 gün arayla iki defa uygulama yapılmıștır. Kontrol dozu için ağaçlara su püskürtülmüștür.

Cizelge 1. Deneme toprağına ait bazı özellikler

Table 1. Some properties of experimental soil

\begin{tabular}{lc}
\hline Toprak özellikleri & Miktar \\
\hline $\mathrm{pH}(1 / 2.5)$ & 7,88 \\
$\mathrm{EC}(1 / 2.5)$ & 0,28 \\
$\mathrm{OM}(\%)$ & 2,4 \\
$\mathrm{CaCO}_{3}(\%)$ & 20 \\
\hline Yarayıșlı besin elementleri $\left(\mathrm{mg} \mathrm{kg}^{-1}\right)$ & \\
\hline $\mathrm{B}$ & 0,46 \\
$\mathrm{Fe}$ & 3,51 \\
$\mathrm{Cu}$ & 2,41 \\
$\mathrm{Zn}$ & 0,89 \\
$\mathrm{Mn}$ & 3,38 \\
$\mathrm{Ca}$ & 7813 \\
$\mathrm{Mg}$ & 243 \\
$\mathrm{~K}$ & 626 \\
$\mathrm{P}$ & 21,6 \\
\hline
\end{tabular}

\section{Yaprakta Bor Analizi}

Bitkilerin B düzeylerinin belirlenmesi amacıyla Temmuz ayında yaprak örnekleri alınmıștır. Alınan örnekler laboratuvara getirilerek çeșme suyu, seyreltik asit $(0,2 \mathrm{~N} \mathrm{HCl})$ ve saf su ile yıkandıktan sonra $65 \pm 5{ }^{\circ} C^{\prime}$ de sabit ağırlığa kadar kurutulup öğütülmüștür. Öğütülmüș bitki örnekleri mikro dalga yakma sisteminde yaș yakıımıștır. Bunun için; 0,4 g bitki örneği alınmıș ve teflon yakma tüpüne konulmuștur. Örneğin üzerine $10 \mathrm{ml}$ konsantre nitrik asit ilave edildikten sonra mikro dalgada yaș yakma fırınında yakılmıștır. Yakılan örneklerin B konsantrasyonları ICP de okunarak hesaplanmıștır (Kacar ve İnal, 2010). 


\section{Meyve Verim ve Bazı Kalite Ölçütlerinin Belirlenmesi}

Meyve verimi ölçümü hassas terazi; meyve eni ve boyu dijital kumpas; sertlik ölçümü penetrometre; suda çözünür kuru madde (ȘCKM) refraktometre ile ve meyve suyunda $\mathrm{pH}$ ise $\mathrm{pH}$ metre cihazıyla ölçülmüștür (Hortwirth, 1960).

\section{İstatistiksel Değerlendirme}

Denemeden elde edilen sonuçların istatistiksel anlamda değerlendirilmesi için COSTAT paket programı kullanılmıș ve her çeșit kendi içinde ayrı ayrı değerlendirilmiștir.

\section{BULGULAR VE TARTIȘMA}

\section{Uygulamaların Yaprak B Konsantrasyonlarına Etkisi}

Elma çeșitlerinin yaprak B konsantrasyonları B uygulamalarından genelde olumlu etkilenmiș olup, Breaeburn çeșidi hariç diğer çeșitlerde yaprak B düzeyleri, yapılan uygulamayla artmıștır. Kontrol koșullarında 32, 29, 28 ve $36 \mathrm{mg} \mathrm{kg}^{-1}$ olan Mondial Gala, Red Chief, Scarlat Spur ve Fuji çeșitlerinin yaprak B düzeyleri, yapraktan B gübrelemesiyle \% $38, \% 28, \% 36$ ve \% 39 oranlarında artıș göstererek, sırasıyla 44, 37, 38 ve $54 \mathrm{mg} \mathrm{kg}^{-1}$ a yükselmiștir (Çizelge 2).

\section{Uygulamaların Meyve Verimi ve Bazı Kalite Ölçütlerine Etkisi}

Yapraktan B uygulamasıyla bütün çeșitlerin verim değerleri artmıș, fakat bu artıș iki çeșitte (Red Chief ve Braeburn) istatiksel anlamda önemli olmamıștır. Mondial Gala, Scarlet Spur ve Fuji çeșitlerinde kontrol koșullarında $5,7 \mathrm{~kg}, 6,8 \mathrm{~kg}$ ve $5,9 \mathrm{~kg}$ olan ağaç bașına düșen verim, sırasıyla \% 25, \% 24 ve \% 7 lik artıșlarla 7,1kg, 8,4kg ve 6,3 kg değerlerine yükselmiștir (Çizelge 3). Yapraktan B uygulaması iki çeșitte meyve ağırlığına etkili olmuș, diğer çeșitlerde etki göstermemiștir. Mondial Gala çeșidinde meyve ağırlığı 165 g' dan 186 g'a, Scarlet Spur çeșidinde de 172 g' dan 188 g' a yükselmiștir (Çizelge 3). Yapraktan B uygulamasının meyvenin SÇKM, $\mathrm{PH}$ ve meyve eti sertliğine etkisi istatistiksel anlamda önemli bulunmamıștır. Meyvenin SçKM değerleri \% 12-14 arasında, $\mathrm{pH}$ değerleri 2, 9-3,4 arasında ve meyve eti sertliği ise $7,4-8,3 \mathrm{~kg} / \mathrm{cm}^{2}$ arasında farklıık göstermiștir (Çizelge 4).

$\begin{array}{cccc}\text { Yapılan analizler sonunda yapraktan } & \text { B } \\ \text { uygulaması elma çeșitlerinin yaprak } & \text { B }\end{array}$ konsantrasyonunu çeșitlere bağlı olarak değișik oranlarda artmıș olup, ortalama artıș oranı yaklașık \% 38 dir. Kontrol koșullarında bütün çeșitler için belirlenen yaprak B düzeyi yeter kabul edilen seviyenin alt sınırlarında olmasına karșılık, uygulamayla bu değerler yeter düzeyin üst sınırlarına çıkmıștır (Jones vd., 1991). Daha önceki çalıșmalarda da belirtildiği gibi, yapraktan uygulama, bitkilerin özellikle mikro element beslenmelerini artırması açısından son derece önemli bir uygulamadır (Erdal vd., 2004; Rawashdeh ve Sala 2013; Rawashdeh ve Sala 2015). Yapraktan B uygulamasının, bitkilerin B beslenmesiyle verim özelliklerine olumlu etkileri, çeșitli bitkilerle yapılan araștırmalarda da ifade edilmektedir (Vasanthu vd., 2015; Dewdar vd., 2015; Güneș vd., 2015). Elma üzerine yapılan bir araștırmada da elmanın mineral beslenmesi üzerine yapraktan gübrelemenin bașarıyla kullanılabileceği vurgulanmıș ve yaprak B içeriğinin yapraktan uygulamayla artırılabileceği ifade edilmiștir (Murtic vd., 2016). Özellikle topraktan beslemenin yapılamadığı, etkili olmadığı veya geç kalındığı zamanlarda yapraktan gübreleme yöntemiyle bitkilerin beslenme düzeyleri iyileștirilmekte bu da verim ve kaliteye olumlu yansımaktadır (Roemheld ve El-Fouly, 1999; Mosa vd., 2015). Literatürde yapraktan B uygulamasının meyvenin sertlik, SÇKM, renk ve meyve suyu pH'sını artırdığına yönelik veriler olmakla birlikte (Wojcik vd. 2008), yapılan bu çalıșmada yaprak uygulamalarını bu kriterler üzerine genel anlamda istatistiksel bir etkisinin olmadığı belirlenmiștir. Bu durumun toprak, çevre ve genotipsel farklıklardan kaynaklanmıș olabileceğini söylemek mümkündür. Her ne kadar istatistiksel anlamda bir değerlendirme yapılmamıș olsa da çeșitlerin yaprak uygulamasından farklı șekillerde etkilendiği ve bu etkinin verim değerlerine

Cizelge 2. Yapraktan B gübrelemesinin elma çeșitlerinin B beslenmesine etkisi

Table 2. Effect of foliar B ferilization on B nutrition of apple cultivars

\begin{tabular}{llllll}
\hline \multirow{2}{*}{ Uyg. } & \multicolumn{1}{l}{ Mondial Gala } & Red Chief & Scarlet Spur & Braeburn & Fuji \\
\cline { 2 - 6 } & Yaprak B konsantrasyonu, $\mathrm{mg} \mathrm{kg}^{-1}$ & & & \\
\hline Y0 & $32 \mathrm{~B}^{*}$ & $29 \mathrm{~B}$ & $28 \mathrm{~B}$ & $38 \mathrm{~A}$ & $36 \mathrm{~B}$ \\
Y1 & $44 \mathrm{~A}$ & $37 \mathrm{~A}$ & $38 \mathrm{~A}$ & $40 \mathrm{~A}$ & $54 \mathrm{~A}$ \\
\hline
\end{tabular}

*Aynı sütunda aynı farkı harfle gösterilen değerler arasında fark önemlidir $(p<0.05)$ 
Cizelge 3. Yapraktan B gübrelemesinin elma çeșitlerinin meyve verimi, meyve ağırlığı, meyve eni ve boyuna etkisi

Table 3. Effect of foliar B fertilization on fruit yield, fruit weight, fruit widht and fruit hight

\begin{tabular}{|c|c|c|c|c|c|}
\hline \multirow{2}{*}{ Uygulamalar } & Mondial Gala & Red Chief & Scarlet Spur & Braeburn & Fuji \\
\hline & \multicolumn{5}{|c|}{ Verim (kg/ağaç) } \\
\hline YO & $5,7 \mathrm{~B}^{*}$ & $6,1 \mathrm{~A}$ & $6,8 \mathrm{~B}$ & $8,0 \mathrm{~A}$ & $5,9 \mathrm{~B}$ \\
\hline \multirow[t]{2}{*}{$\mathrm{Y} 1$} & $7,1 \mathrm{~A}$ & $6,8 \mathrm{~A}$ & $8,4 \mathrm{~A}$ & $8,3 \mathrm{~A}$ & $6,3 \mathrm{~A}$ \\
\hline & \multicolumn{5}{|c|}{ Meyve ağırlığı (g/meyve) } \\
\hline YO & $165 \mathrm{~B}$ & $156 \mathrm{~A}$ & $172 \mathrm{~B}$ & $172 \mathrm{~A}$ & $166 \mathrm{~A}$ \\
\hline \multirow[t]{2}{*}{$\mathrm{Y} 1$} & $186 \mathrm{~A}$ & $163 \mathrm{~A}$ & $188 \mathrm{~A}$ & $181 \mathrm{~A}$ & $174 \mathrm{~A}$ \\
\hline & \multicolumn{5}{|l|}{ Meyve eni (mm) } \\
\hline YO & 66 & 70 & 74 & 62 & 66 \\
\hline \multirow[t]{2}{*}{$\mathrm{Y} 1$} & 72 & 70 & 73 & 69 & 66 \\
\hline & \multicolumn{5}{|c|}{ Meyve boyu (mm) } \\
\hline YO & 73 & 74 & 81 & 67 & 72 \\
\hline Y1 & 75 & 79 & 80 & 73 & 73 \\
\hline
\end{tabular}

*Aynı sütunda farklı harfle gösterilen değerler arasında fark önemlidir ( $p<0,05)$

Cizelge 4. Yapraktan B gübrelemesinin elma meyvesinin SçKM, pH ve meyve sertliği üzerine etkisi

Table 4. Effect of foliar $B$ fertilization on soluble solids, $\mathrm{pH}$ and firmness of apple fruit

\begin{tabular}{|c|c|c|c|c|c|}
\hline \multirow{2}{*}{ Uygulamalar } & Mondial Gala & Red Chief & Scarlet Spur & Braeburn & Fuji \\
\hline & \multicolumn{5}{|l|}{ SÇKM, \% } \\
\hline YO & 12 & 13 & 12 & 13 & 12 \\
\hline \multirow[t]{2}{*}{ Y1 } & 12 & 14 & 13 & 13 & 12 \\
\hline & \multicolumn{5}{|l|}{$\mathrm{pH}$} \\
\hline YO & 3,1 & 3,1 & 3,1 & 2,9 & 2,9 \\
\hline \multirow[t]{2}{*}{ Y1 } & 3,3 & 3,3 & 3,4 & 3,0 & 3,2 \\
\hline & \multicolumn{5}{|c|}{ Meyve eti sertliği $\left(\mathrm{kg} / \mathrm{cm}^{2}\right)$} \\
\hline YO & 7,5 & 7,6 & 8,1 & 7,9 & 8,3 \\
\hline Y1 & 7,4 & 7,4 & 8,3 & 7,7 & 8,3 \\
\hline
\end{tabular}

de farklı șekillerde yansıdığı dikkati çekmektedir. Bu durum, daha önce yapılan değișik çalıșmalarda da görülmüș ve bitkiler aynı ortamda yetișmiș olsalar dahi besin elementlerinde yararlanma oranları birbirlerinden farklı olabileceği ifade edilmiștir. Bu olay farklı bitki türleri arasında olabildiği gibi aynı türe ait genotipler arasında da görülebilmektedir (Taban ve Erdal, 2000; Küçükyumuk ve Erdal, 2009; Küçükyumuk ve Erdal, 2011 1). Bu değerlendirmeler genellikle bitkilerin topraktaki besin elementlerinden yararlanma oranları üzerine olmakla beraber, yapraktan beslenme de de bu tür farklılıkların olduğu görülmüș ve farklılıklar üzerine yaprağın çeșitli morfolojik ve fizyolojik özelliklerinin önemli etki yaptığı belirtilmiștir (Hull, 1970; Niinemets ve Kull, 2003; Fernández ve Eichert, 2009).

\section{SONUC̣LAR}

Yapraktan B uygulaması “Braeburn” çeșidi hariç diğer elma çeșitlerinin yaprak B konsantrasyonlarını önemli derecede artırmıștır. En fazla artıș "Fuji” çeșidinde görülmüș olup, bu çeșidin incelenen çeșitler içerisinde B uygulamalarından en çok etkilenen çeșit olduğu, buna karșılık "Braeburn" çeșidinin B uygularından etkilenmediği görülmüștür. Yaprak B uygulamaları 3 çeșitte toplam meyve verimini de artırmıștır. Elde edilen verim artıșları yaprak B konsantrasyonundaki artıșlara paralel bir eğilim göstermemekle beraber, bütün çeșitler için ortalama \% 12 lik bir verim artıșı elde edilmiștir. Bu durumda yaprak B uygulaması, özellikle "Mondial Gala" ve "Scarlet Spur" gibi yaklașık \% 25 lik verim artıșlarının elde edildiği ve denemenin yürütüldüğü koșullara özdeș koșullarda yetiștirilen çeșitlerde önerilebilir.

\section{Teșekkür}

Bu çalıșma Süleyman Demirel Üniversitesi BAP yönetim birimi tarafından desteklenmiștir.

\section{KAYNAKLAR}

Bergmann W (1992). Nutritional Disorders of Plants. Development Visual and Analytical Diagnosis. Jena, Germany: Gustav Fischer.

Boyacı S, Çağlar S A (2009). Study on the production of branched apple tree under nursery condition in Turkey. TABAD, Tarım Bilimleri Araștırma Dergisi, 2(1): 107-111. 
Brackmann A, Thewes F R, Anese R D O, Linke Junior W (2016). Pre-harvest boron application and it's relation with the quality of 'Galaxy' apples after harvest and controlled atmosphere storage. Ciência Rural, 46(4): 585-589.

Dewdar M D H, Abbas M S, Gaber E I, Abd El-Aleem H A (2015). Influence of time addition and rates of boron foliar application on growth, quality and yield traits of sugar beet. Int. J. Curr. Microbiol. App. Sci, 4(2): 231-238.

Erdal I, Kepenek K, Kızılgöz I (2004). Effect of foliar iron applications at different growth stages on iron and some nutrient concentrations in strawberry cultivars. Turkish Journal of Agriculture and Forestry, 28(6): 421-427.

Eyüpoğlu F, Güçdemir i H, Kurucu N, Talaz S (2000). Orta Anadolu Topraklarının Bitkiye Yarayıșlı Bor Bakımından Genel Durumu. Toprak ve Gübre Araștırma Enstitüsü Yayını, Ankara S, $1-47$.

Eyüpoğlu F, Kurucu N, Güçdemir İ, Talas S (2000). Boron status of Central Anatolian. International Conference Sustainable Land Use and Management, 10-13 June 2002, pp. 55-61, Çanakkale, Turkey.

FAO (1990). Micronutrient Assessment at the Country Level: An International Study. FAO Soils Bulletin 63. Rome.

Fernández V, Eichert T (2009). Uptake of hydrophilic solutes through plant leaves: current state of knowledge and perspectives of foliar fertilization. Critical Reviews in Plant Sciences, 28(1-2): 36-68.

Günes A, Köse C, Turan M (2015). Yield and mineral composition of grapevine (Vitis vinifera L. cV. Karaerik) as affected by boron management. Turkish Journal of Agriculture and Forestry, 39(5): 742-752.

Hortwirth N (1960). Official methods of analysis. Chapter 29, Sugar and Sugar Products, AOAC, Benjamin Fraklin Station, Washington DC

Hull H M (1970). Leaf structure as related to absorption of pesticides and other compounds. In Residue Reviews/Rückstands-Berichte (pp. 1-150). Springer New York.

Jones Junıor J B, Wolf B, Mills H A (1991). Plant Analysis Handbook. Athens, GA: Micro-Macro Publ.

Kacar B., Katkat A V (2009). Bitki Besleme. Nobel Yayınevi. Yayın No; 849, Ankara.

Kacar B, İnal A (2010). Bitki Analizleri, Nobel Yayınevi, Yayın No.1241. Ankara.

Küçükyumuk Z, Erdal i (2009). Rootstock and variety effects on mineral nutrition of apple trees. Süleyman Demirel Üniversitesi, Ziraat Fakültesi Dergisi, 4(2): 8-16

Küçükyumuk Z, Erdal I (2011). Rootstock and cultivar effect on mineral nutrition, seasonal nutrient variation and correlations among leaf, flower and fruit nutrient concentrations in apple trees. Bulgarian Journal of Agricultural Science, 17: 633-641.

Lindsay W L, Norvell W A (1969). Development of A DTPA micronutrient soil test. Soil Science Society of American Proceeding 35, 600-602.
Lötze E, Hoffman E W (2014). Foliar application of calcium plus boron reduces the incidence of sunburn in 'Golden Delicious' apple. The Journal of Horticultural Science and Biotechnology, 89(6): 607-612.

Marschner H (2011). Marschner's Mineral Nutrition of Higher Plants. Academic Press.

Mosa Wfaeg, El-Megeed N AA, Paszt L S (2015). The effect of the foliar application of potassium, calcium, boron and humic acid on vegetative growth, fruit set, leaf mineral, yield and fruit quality of 'Anna' apple trees. American Journal of Experimental Agriculture, 8(4): 224-234.

Murtic S, Civic H, Đuric M, Šekularac G, Kojovic R., Kulina M, Krsmanovic M. Foliar (2016). Nutrition in apple production. African Journal of Biotechnology, 11 (46): 10462-10468.

Neilsen G H, Neilsen D, Peryea F J, Fallahi E, Fallahi B (2008). Effects of mineral nutrition on fruit quality and nutritional disorders in apples. In VI International Symposium on Mineral Nutrition of Fruit Crops 868 (pp. 49-60).

Niinemets U, Kull K (2003). Leaf structure vs. nutrient relationships vary with soil conditions in temperate shrubs and trees. Acta Oecologica, 24(4): 209-219.

Rawashdeh H, Sala F (2013). Effect of different levels of boron and iron foliar application on growth parameters of wheat seedlings. In African Crop Science Conference Proceedings, 11, pp. (861-864).

Rawashdeh H, Sala F (2015). Foliar application with iron as $A$ vital factor of wheat crop growth, yield quantity and quality: A Review. International Journal of Agricultural Policy and Research 3: 368-376.

Roemheld V, El-Fouly M M (1999). Foliar nutrient application: Challenge and limits in crop production. In Proc. 2nd International Workshop on" Foliar Fertilization" April (pp. 4-10).

Taban S, Erdal I (2000). Bor uygulamasının değișik buğday çeșitlerinde gelișme ve toprak üstü aksamda bor dağıımı üzerine etkisi. Turk. J. Agric. For., 24, 255-262.

TOVEP (1991). Türkiye Toprakları Verimlilik Envanteri. T.C Tarım Orman ve Köy İșleri Bakanlığı, Köy Hizmetleri Genel Müdürlüğü Yayınları

Vasanthu S, Kumar K S, Padmodaya B, Reddy C (2015). Effects of foliar application of boron on leaf boron content and yield of papaya cv. Red Lady. Journal of Applied Horticulture, 17(1): 76-78.

Wójcik P, Cieslinski G, Mika A (1999). Apple yield and fruit quality as influenced by boron applications. Journal of Plant Nutrition, 22(9): 1365-1377

Wojcik P, Wojcik M, Klamkowski K (2008). Response of apple trees to boron fertilization under conditions of low soil boron availability. Scientia Horticulturae, 116(1): 58-64.

Wolf B (1971). The determination of boron in soil extracts. Plant materials, composts, manures, and water and nutrient solutions. Soil Science and Plant Analysis, 2: 363-374. 